\title{
LA MATERNIDAD EN EL IMAGINARIO DE LAS ESCRITORAS VASCAS
}

\author{
GEMA LASARTE LEONET \\ Universidad del País Vasco
}

Recibido/15/07/2011

Aceptado/25/09/2011

\section{Resumen}

Este artículo estudia y analiza la representación de la maternidad en la narrativa vasca desde 1979 hasta el año 2010. La autoría femenina, los personajes femeninos protagonistas y la maternidad como eje temático son los criterios establecidos para delimitar el corpus de esta investigación. La crítica feminista y la narratología han sido los paradigmas teórico-metodológicos aplicados en el análisis de los ejes temáticos y de los personajes. La aportación más significativa de esta investigación es la ratificación de que la maternidad, que constituye una piedra angular dentro del pensamiento feminista, tiene una presencia y una representación análogas en la literatura vasca, en tanto que el $66 \%$ de las obras analizadas abordan la temática de la maternidad.

Palabras claves: maternidad, literatura, personajes femeninos, cuerpo.

\begin{abstract}
This article studies and analyses the representation of motherhood in the Basque narrative from 1979 until the year 2010. Female authorship, the female characters, protagonists and motherhood as thematic axis, are established criteria to delimit the corpus of this research. Feminist criticism and the narrative have been methodological elements paradigms applied in the analysis of the themes and characters. The most significant contribution of this research is the ratification that motherhood, which is a cornerstone in feminist thought, has a similar representation in Basque literature, while 66 analyzed works dealt with maternity as a thematic axis.
\end{abstract}

Keywords: maternity, literature, female characters, body.

Feminismo/s 18, diciembre 2011, pp. 203-223 


\section{Introducción}

Este artículo estudia la representación de la maternidad en la narrativa vasca desde 1979 hasta el año 2010. Para dicho estudio nos hemos centrado en el análisis de novelas escritas por narradoras vascas y protagonizadas por personajes femeninos. La autoría femenina, los personajes femeninos protagonistas y la maternidad como eje temático son los criterios establecidos para delimitar el corpus de esta investigación. Tras una breve introducción y unas aportaciones teórico-metodológicas, se efectúa un repaso por las distintas maternidades con el objetivo de averiguar las analogías existentes entre la realidad social y la realidad literaria de la época analizada. Para ello, partimos de la hipótesis del concepto de homología del crítico marxista Lucien Goldmann ${ }^{1}$ que lo define como una analogía entre las estructuras sociales y las literarias. Para determinar las analogías referentes a la maternidad, llevamos a cabo, en un primer apartado, un recorrido por todo el corpus, sin pretender un estudio conciso y detallado de cada novela, sino realizar un agrupamiento de las mismas que nos permita interpretar los distintos aspectos de la maternidad que destacan en el imaginario de las narradoras vascas.

En segundo lugar y dentro del mismo apartado, se analizan de forma más exhaustiva las dos novelas que mejor reflejan las dos posturas más extremas sobre la maternidad en la literatura vasca: Zergatik Panpox $(1979)^{2}$ de Arantxa Urretabizkaia que celebra la maternidad y Eta emakumeari sugeak esan zion $(1999)^{3}$ de Lourdes Oñederra que constituye una clara negativa a la procreación. Para concluir con estas aproximaciones textuales, hemos ahondado también en las nuevas paternidades, temática novedosa en la narrativa vasca, y que aparece tímidamente en varias novelas, como en Sisifo maiteminez $(2001)^{4}$ en la que Laura Mintegi incorpora esta temática innovadora. Para

1. La crítica marxista abordó como tema de estudio la dimensión social del personaje literario. Lucien Goldmann aportó el concepto de homología, entendido como analogía entre las estructuras literarias y las estructuras sociales. Referencia bibliográfica: GOLDMAnN, Lucien. Para una sociología de la novela. Ciencia Nueva, Madrid, 1967.

2. Esta novela está traducida al castellano: ¿Por qué Panpox? (1995), Orain.

3. Traducida al castellano: Y la serpiente dijo a la mujer (2000), Bassarai.

4. Traducida al castellano: Sisifo enamorado, (2003), Txalaparta.

Feminismo/s 18, diciembre 2011, pp. 203-223 
finalizar la parte dedicada al análisis de las distintas representaciones, hemos seleccionado el citado texto y por último, hemos dedicado sendos epígrafes a las conclusiones y a la bibliografía.

\section{Aportaciones teórico-metodológicas}

La elección de un mismo semema en el análisis de los textos puede llegar a ser un objeto de estudio sorprendentemente revelador, como augura Geraldine Nichols: «Poner de relieve el tratamiento de la procreación puede iluminar constelaciones de significados hasta ahora ocultos, a la vez que ofrecer una radiografía de los tiempos que corren $»^{5}$. En este sentido, el tema de la reproducción o la maternidad puede facilitar el estudio de temas como las complejas relaciones de pareja, la influencia de la madre o la desigualdad y la injusticia, temas que funcionan, asegura Nichols, como sinécdoque de una serie de prácticas que implican la desigualdad.

En relación a la maternidad como eje temático, la crítica feminista ha visualizado la maternidad desde distintas ópticas. Así, parte de los discursos feministas del siglo pasado fueron profundamente anti-maternos (Beauvoir, 2005; Firestone, 1976; Rich, 1996). Simone de Beauvoir habla de la maternidad como único destino posible, Shulamith Firestone vislumbra la maternidad como una apropiación de los cuerpos de las mujeres como recurso de reproducción del patriarcado y Adrianne Rich diferencia la maternidad como institución y la maternidad como una experiencia física y psicológica por parte de las mujeres y, junto a ello, se produce una reapropiación del cuerpo. Esta reivindicación de lo corporal como vía de conocimiento y poder deriva en planteamientos positivos de la maternidad. De esta manera, Sara Ruddick (1984) propone una aproximación del feminismo al pacifismo, Shiva Vandana (1995) propugna el eco-feminismo que retoma la analogía de la mujer con la tierra. Desde otra perspectiva, el feminismo de la diferencia (Irigaray 1974, Cisoux, 1975) trata de reconocer la tarea de la reproducción, menospreciada por los hombres e inicia así el discurso del orgullo del cuerpo.

Este breve recorrido que resume la centralidad del debate feminista sobre el tema de la maternidad, en la actualidad y en el ámbito nacional, ofrece nuevas lecturas. Maria Luz Esteban ${ }^{6}$ afirma que en los últimos treinta años se han ido produciendo modificaciones claras en las regulaciones y controles sobre los cuerpos de las mujeres y habla de las diferentes posiciones feministas

\footnotetext{
5. NiCHOLS, Geraldine. «El procrear, pro y contra», en REDONDO, Alicia (ed.): Mujeres novelistas, Madrid, Taurus, 2003: 192.

6. EsteBAn, Maria Luz. Antropología del cuerpo. Bellaterra, Barcelona, 2004: 32.
} 
respecto al cuerpo. En este sentido, una forma de entender el cuerpo sería la que ofrece la perspectiva constructivista en la que se defiende que la identidad y la subjetividad se construyen socialmente. Se trataría, según Esteban, de presentar a las mujeres no como víctimas sino como agentes de sus vidas capaces de generar propuestas alternativas que compensen su situación de desventaja. Un ejemplo claro de ello lo constituyen las Madres de la Plaza de Mayo que cuestionan el sistema político en su conjunto desde la asunción del rol de madres. Esta posición de empoderamiento y visión de la maternidad nos muestra otra perspectiva de estudio desde la crítica feminista.

En este mismo sentido, Miren Llona en el capitulo «Patriotic Mothers of Basque Nationalism: Women's Action during the Spanish Second Republic in the Basque Country» (2010) al indagar en la vida de Polixene Astrabudua, retoma el modo de análisis que Cherry Moraga define como «Theory in the flesh». Esta teoría entiende la construcción de la identidad como algo inseparable de la experiencia física y de la huella dejada por esa experiencia en el cuerpo. Nosotras hemos querido analizar la maternidad en este artículo siguiendo el método propuesto por Moraga, esto es, como una experiencia física vivida desde el cuerpo y al mismo tiempo como construcción de la identidad.

Elixabete Imaz en su tesis doctoral (2007) afirma que las mujeres pasan la mayor parte de su vida evitando activamente el embarazo y por ello adquiere pertinencia preguntarse por las situaciones concretas que promueven que la maternidad se vea como plausible y deseable. Añade la autora que la conversión de una mujer en madre es un tránsito social que no puede reducirse al simple acontecer fisiológico del parto sino que es, además, un proceso de aprendizaje y socialización. En otras palabras: la conversión de una mujer en madre se traduce en la gestación de una madre en un complejo social. Por otra parte, el crítico literario marxista George Luckás ${ }^{7}$ reconoció al personaje literario su dimensión social asegurando que este se construía en una dialéctica abierta con la realidad social.

Si para el análisis de los distintos aspectos discursivos ${ }^{8}$ de la maternidad esta investigación ha requerido de la crítica feminista, para el estudio de los

7. En la crítica marxista tiene singular importancia el concepto de héroe problemático del cual es autor George Luckás. Luckás habló de la dimensión social del personaje y de su interacción con la sociedad. Para este punto recomendamos leer su obra Teoría de la novela (1971), se cita en las referencias bibliográficas.

8. El discurso entendido como un conjunto de afirmaciones o enunciados (que, adviértase, pueden o no manifestarse como un conjunto de textos) que están unificados porque tienen un objeto de análisis común ya que articulan de modo singular el conocimiento sobre tal objeto, según Maria José Vega (2003:83). Ver referencia bibliográfica.

Feminismo/s 18, diciembre 2011, pp. 203-223 
personajes ha recurrido a la narratología. Desde el punto de vista narratológico hemos tenido en cuenta las aportaciones de Algirdas Julius Greimas (1983) y las revisiones a su teoría formuladas por Mieke Bal (1985) y Sholomith Rimmon-Kenan (1983). Es interesante observar que al concepto del personaje como unidad sintáctica o posición estructural, Bal agregue la teoría del personaje como una unidad semántica completa. Carmen Boves, (1993) va más allá e incorpora la pragmática como aspecto importante a la hora del estudio del personaje.

La narratología aporta conceptos fundamentales para el estudio del personaje: funciones (Greimas) $)^{10}$, focalización (Genette $)^{11}$, discurso (Friedman) ${ }^{12} \ldots$ pero es básicamente mediante este último recurso, el del componente discursivo, que el personaje comienza a hablar solo o comienza a mezclarse con el discurso del narrador. Silvia Burunat en su obra El monólogo interior como forma en la narrativa española (1980) señala que del mismo modo que el psiquiatra coloca al paciente en el sofá ocupando él una posición invisible con respecto a aquel que se convierte en el sujeto que habla, expresando todo lo que fluye por su mente y de esta manera una idea produce otra, un recuerdo sugiere otro hasta que la conciencia se convierte en un hecho psíquico conocido, el novelista somete a sus personajes a un tratamiento semejante,

9. Para el estudio del personaje literario consideramos de estudio obligatorio los autores mencionados: Greimas, Bal y Rimmon Kenan en las obras indicadas en las referencias bibliográficas. Disertan sobre las funciones gramaticales que cumple el personaje en el texto. Bal resalta aspectos semánticos en su obra Teoría de la narrativa (1985) en la página 87. Carmen Boves incorpora características del personaje de aspectos más pragmáticos en su obra Teoría de la novela (1993) en la página 157.

10. Las funciones gramaticales del personaje y el concepto de paradigma actancial son de Greimas. El esquema de los actantes lo constituyen seis agentes: los sujetos-objetos de la acción. El sujeto ofrece un principio dinámico a la acción respondiendo al deseo, al miedo, las ganas.... Todo ello constituye el sentido del objeto, es decir, lo que el sujeto quiere lograr. De esta forma, el deseo, el miedo o las ganas unen al sujeto y al objeto en la función gramatical. El destinador incide directamente en el sujeto, le exige distintos quehaceres. El destinatario a su vez puede ser el beneficiario de la acción; muchas veces puede ser el mismo protagonista. Los ayudantes y contrarios del sujeto pueden ayudar o poner trabas a los objetivos del sujeto. En resumen, el paradigma actancial se construye de la siguiente forma: Destinador/Objeto/Destinatario; Ayudante/Sujeto/ Oponente.

11. El narratólogo Gérad Genette en Figuras III hace interesantes aportaciones al concepto de Focalización que hasta entonces se confundía con las funciones narrativas.

12. Friedman analiza los distintos estilos para expresar los sentimientos y los pensamientos de los personajes: el estilo directo, el estilo indirecto, el estilo indirecto libre... todos ellos formas de encauzar la voz, el pensamiento de los personajes. En «Point of view in fiction: the development of critical concept». 
induciendo a sus criaturas a hablar por sí mismas en un lenguaje que es inherente a su mentalidad.

Las críticas feminista y marxista enfatizan la dimensión social del personaje. Uno de los representantes más conocidos de la crítica marxista, George Lukács, sostiene que el personaje mantiene una constante dialéctica con su entorno; Lucien Goldmann, creador del estructuralismo genético, subraya la homología que existe entre el personaje literario y la persona que habita en sociedad. La crítica feminista acomete en 1970 el estudio de las figuras femeninas creadas por los hombres (Millet, 197013) y desde entonces, el estudio de las figuras e imágenes de las mujeres cobrará una importancia incuestionable. Rich ha denominado «revisión» al acto de mirar hacia atrás, de ver con ojos nuevos, de entrar en un texto antiguo desde una nueva mirada crítica. A finales del siglo XVIII las mujeres ya no solo estaban intentando escribir, estaban concibiendo mundos de ficción en los que las imágenes y convenciones patriarcales se revisaban de forma severa y radical. Por su parte, Susan Gilbert, y Sandra Gubar, ${ }^{14}$ realizan un interesante estudio de los personajes femeninos creados por las autoras del siglo XIX.

\section{Distintas representaciones de la maternidad}

En el periodo de tiempo que nos ocupa (1970-2010), las mujeres escritoras vascas han configurado una treintena de narraciones con personajes protagonistas femeninos. En casi todas ellas aparece la maternidad, a excepción de las obras de la autora labortana, Itxaro Borda, que no la menciona; únicamente, en la novela Bizi nizano munduan (1996) nos sugiere la historia de un hijo negado, bastardo, de uno de los personajes femeninos secundarios. Asimismo, Garazi Goia, Nora Arbelbide e Iratxe Esnaola, en sus respectivas obras Bi hitz (2008), Goizeko zazpiak (2006) y Galerna (2009) eluden tratar el tema de la maternidad. Por ese motivo, estas obras han sido excluidas de nuestro estudio. Todas las demás autoras, dentro de la acotación cronológica elegida para el análisis, abordan la temática de la maternidad y la relacionan con el personaje protagonista femenino.

En el siguiente epígrafe, realizamos una aproximación textual a las novelas que contemplan los distintos aspectos de la maternidad que las escritoras

13. Millet, Kate publicó por vez primera Política Sexual en 1969 e inició el estudio y tratamiento que el hombre daba a la imagen de la mujer.

14. Gilbet, Susan y GubAr, Sandra son las autoras de un clásico de la literatura, La loca del desván. La escritora y la imaginación literaria del siglo XIX. Es el primer ensayo que profundiza en el estudio del tratamiento de los personajes literarios femeninos. Ver referencia bibliográfica.

Feminismo/s 18, diciembre 2011, pp. 203-223 
vascas han abordado en su narrativa mediante sus personajes protagonistas femeninos. Este primer apartado tiene como objetivo presentar de forma sistemática los aspectos, las temáticas y el posicionamiento del personaje femenino en el paradigma actancial. El segundo apartado ofrece una aproximación textual más profunda de la maternidad. Para ello, hemos seleccionado tres novelas de gran relevancia en la novelística vasca: Zergatik Panpox, la primera novela que aporta a la literatura vasca un sujeto protagonista femenino moderno, Eta emakumeari sugeak esan zion la primera novela en la literatura vasca que recibe un premio tan importante como polémico ${ }^{15}$, y por último Sisifo maiteminez (2001), según la crítica vasca, el texto más significativo de una de las autoras más prolíferas de la literatura vasca actual, Laura Mintegi. Estas tres obras ofrecen tres miradas, tres formas muy distintas de entender la maternidad y es esa la razón principal de haberlas seleccionado para un estudio más pormenorizado.

\subsection{Un breve repaso por las distintas maternidades}

\subsubsection{Las maternidades temidas y obligadas}

Las obras de Laura Mintegi, Bai... baina ez (1986), de Sonia González, Ugerra eta kedarra (2003) y, por último, de Aitziber Etxeberria, Tango urdina (2003) representan una maternidad no deseada. En concreto, las tres novelas materializan una maternidad temida ya que lo que la niña descubre a su alrededor no es un vacío por la madre, sino unos discursos que se empeñan en asegurar que es negativo e imperfecto. ${ }^{16}$ Las tres sujetos protagonistas (Rosa, Kat, Marga) no desean la maternidad, las experiencias sociales que configuran sus vidas han contribuido a negar la maternidad. Rosa es huérfana de madre, Kat vive en un mundo de violencia y de drogas, donde sobrevivir es lo más acuciante y Marga sufre a diario los malos tratos de su marido. Marga ha abortado, y posteriormente tiene una hija, muy a pesar del marido que deseaba un niño. Estos personajes literarios construidos desde la semántica de la violencia de género, rehúsan la maternidad como objeto. En el paradigma actancial se observa que la sociedad funciona como destinador para enraizar en Rosa, Kat y Marga el rechazo a la maternidad. Los abusos sexuales, la pobreza y el mal trato son los ejes temáticos sobre los que se sustentan estas narraciones y

15. Recibió varios premios: Premio de la Crítica y el Premio Euskadi que tuvo gran controversia en la prensa: se habló de que ganó el premio por ser mujer.

16. BENGOECHEA, Mercedes.»Mi madre es... un hueco en el espacio: discursos poéticos y lingüísticos sobre insignificancia materna», DE LA CONCHA, Ángeles y OSBORNE, Raquel (ed.): Las mujeres y los niños primero. Icaria, Barcelona, 2004: 103. 
los campos semánticos que significan a los personajes, por lo tanto, la función gramatical de estos personajes se inscribe en el rechazo a la maternidad.

Otro de los aspectos que redunda en los aspectos negativos de la maternidad es la maternidad obligada. En este punto vamos a introducir a las madres veteranas, así tenemos a Graziana de Ixiar Rozas (1972) que aparece en Edo zu edo ni (2000), a Teresa de Uxue Alberdi (1984) en Aulki-jokoa (2009), a Elena de Karmele Jaio en Musika airean (2009) y las tres protagonistas de Urretabizkaia en Hiru Mariak (2010). Todos estos personajes literarios rondan entre los 65-85 años y nos remiten a la afirmación de Beauvoir en torno a que la maternidad tiene que dejar de ser un destino para convertirse en un proyecto, es decir, tiene que ser elegida libremente. Estos personajes literarios han nacido con el siglo, han sufrido la guerra civil española, y han vivido la experiencia de la maternidad obligatoria. Beauvoir afirma que este tipo de madres son las madres dolorosas, frustradas, que no han tenido expectativas en la vida y que han vivido encerradas. Graziana, Teresa, Elena y las tres Marías son mujeres casadas que han vivido encerradas en sus casas hasta que han muerto sus esposos y se han puesto a pensar en el pasado y a cuestionar el futuro. Elena, hasta que muere su marido, no se da cuenta de que lo que realmente le gusta a ella es vivir sola, Graziana se queja de que a sus hijos no les importa quién era antes de ser madre.

Son madres que en el paradigma actancial cumplen el cometido de la familia y la maternidad, pero la edad las libera de ese compromiso y cambian las funciones en el texto porque estas mujeres mayores quieren ser sujetos de sus acciones. No obstante, es importante reseñar en este punto, la visibilidad que adquieren estas protagonistas con la edad. Es de resaltar desde el punto semántico y pragmático la representación de estas mujeres con sus cuerpos envejecidos y medicalizados, cuando la norma estética marca el culto a la juventud. En la actualidad, las personas viven el proceso de envejecimiento en un entorno de ausencia de representación. ${ }^{17}$

\subsubsection{Madres abandonadas}

Bajo este título vamos a incluir Koaderno gorria (1998) de Arantxa Urretabizkaia y Nerea eta biok (1994) de Laura Mintegi. Los personajes protagonistas de estas novelas tienen características similares: son madres de una edad comprendida entre los 30 y los 40 años, gozan de un cierto estatus, poseen un

17. KoGAN, Libia publicó un artículo muy interesante en relación a los cuerpos. «Jóvenes y viejos: ¿el cuerpo como locus de identidad?». En Revista Latinoamericana de Estudios sobre Cuerpos, emociones y Sociedad. Argentina, 2011: 17.

Feminismo/s 18, diciembre 2011, pp. 203-223 
trabajo remunerado, muestran inquietudes políticas y han sido abandonadas por sus respectivos esposos. Las madres analizadas, sin nombre, son madres agentes, independientes que equiparan la maternidad al trabajo profesional y al activismo político. Koaderno Gorria relata la historia de una madre que milita en ETA y cuyo marido secuestra a sus hijos y se los lleva a Venezuela. La madre no tiene ninguna información sobre sus hijos y comienza a escribir un cuaderno rojo. En relación a Koaderno Gorria, la crítica y profesora Maria José Olaziregi ${ }^{18}$ afirma que este personaje nos habla del aspecto social y político de la maternidad. Olaziregi va más allá y señala que de la misma forma que le robaron los hijos, también le robaron la maternidad y la familia. Y esto constituiría la tragedia más significativa de esta obra: la negación del desarrollo personal de la mujer por parte de la sociedad machista.

En Nerea eta biok, Isabel la protagonista, es una profesora de la Universidad que tiene dos hijos mayores cuyo esposo la abandona porque la vida de padre no le satisface plenamente y quiere dar un giro a su vida y vivir nuevas experiencias. Isabel reflexiona sobre esta actitud de su marido y llega a la conclusión de que no estaba preparado para la paternidad. Tanto la madre de Koaderno Gorria como Isabel hablan en primera persona y tienen por objeto rehacer sus vidas.

\subsubsection{Madres simbólicas}

Yolanda Arrieta nos muestra en la novela Jostorratza eta haria (2001) a una madre simbólica que teje la historia de su familia. Esta madre, Miren, cuenta la historia de su familia a la hija que está por nacer (Mirentxu), para hacerla participe de la palabra y de la realidad en cual le va a tocar vivir, esto es, la madre mediante la palabra enseña a hablar y enseña, para toda la vida, el sentido de la realidad y de la verdad. ${ }^{19}$ Como expresaría Luce Irigaray, la madre simbólica de Jostorratza eta haria, ella crea su propio lenguaje y su propio discurso a través de las historias transmitidas por sus abuelas. El relato obedece a una isotopía propia del hilado y a una sintaxis nueva, tejida despacio, de una forma visual y fácil de comprender. Es una madre simbólica que teje su historia a retazos, recreando así la metáfora de la cultura clásica griega que establece paralelismos entre la literatura y la costura. ${ }^{20}$ Pero también se trata de un cuerpo embarazado y de una madre que responde al concepto de

18. Olaziregi, María José, Euskal eleberriaren historia. Labayru Ikastegi, Amorebieta-Etxanoko, 2002107.

19. Rivera Garretas, Milagros. La diferencia sexual en la historia. PUV, Valencia, 2004: 57.

20. KORTAZAR, Jon analiza Jostorratza eta Haria en Euskal Literatura XX, 2003: 284. 
agencia (Esteban, 2004), obviando la construcción de su propia subjetividad y la identidad de la niña que todavía no ha nacido.

Esta madre transmisora de la memoria colectiva y de la cultura oral ha tenido gran presencia en la cultura vasca. Baste citar a Mercedes Ugalde que en su tesis doctoral Mujeres y nacionalismo. Génesis y desarrollo de Emakume Abertzale Batza 1906-1936 (1993) y a Maite Núñez Betelu la cual en su tesis inédita Género y construcción nacional en las escritoras vascas (2001) dan testimonio de ello. De las treinta novelas investigadas, Miren de Jostorratza eta haría es la única figura femenina protagonista que retoma este papel de sujeto trasmisor de la cultura sobradamente constatado en la realidad social y literaria vasca anterior a la época contemporánea. Esta realidad evidencia el concepto de homología de Goldmann, en tanto que actualmente en la realidad social la madre vasca no es la portadora ni la transmisora de la lengua y la cultura vasca.

\subsection{Zergatik Panpox: recreación de la maternidad}

Dentro del corpus a estudiar hay dos novelas que recrean la maternidad desde la primera hasta la última página. Se trata de Bi marra arrosa (2009) de Jasone Osoro y Zergatik Panpox (1979) de Arantxa Urretabizkaia. Analizaremos en profundidad Zergatik Panpox porque la madre protagonista del relato es el primer personaje femenino moderno protagonista de la narrativa vasca. ${ }^{21}$

Zergatik Panpo ${ }^{22}$ nos ofrece un paradigma de familia monoparental. «La maternidad monoparental no sólo es una posición familiar nueva, sino una realidad compleja y significativa en curso, que las mujeres tras una experiencia de separación y/o divorcio van dotando de sentido». ${ }^{23}$

Arantxa Urretabizkaia elabora esta familia monoparental en su relato y se adscribe al eje temático del abandono. La madre, sin nombre, recuerda constantemente el abandono de su marido y su lucha por constituir una familia.

Por encima de estas constantes alusiones al abandono y la ausencia, la novela recrea la relación madre-hijo, una relación corporal y cósmica. Susan

21. LASARTE, Gema en su tesis doctoral Pertsonaia protagonista femeninoen ezaugarriak eta bilakaera euskal narratiba garaikidean (2011) incorporó el personaje femenino de Zergatik Panpox en la historiografía crítica de los personajes literarios de la literatura vasca, siendo la primera protagonista femenina de la historia literaria vasca.

22. Zergatik Panpox se escribirá de aquí en adelante como ZP.

23. BARRON, Silvia «Introducción: La maternidad monoparental», en Las mujeres y los niños primero. Op. cit., p. 229.

Feminismo/s 18, diciembre 2011, pp. 203-223 
Rubin Suleiman ${ }^{24}$ al criticar la obra Maternité de Chantal Chawaf, expresa que esta unía el ejercicio de la escritura femenina con el hecho biológico de la maternidad. La experiencia central alrededor de la cual gira su escritura, indica Suleiman, es la experiencia emocional y física de la maternidad y del amor maternal, dotándole así de una trascendencia casi cósmica. Lo mismo se podría señalar en la obra de Urretabizkaia. «Lurraren sabeleko suzko odola sustraien muturretatik sartzen zait, zuri loa sudurreko hegaletatik sartzen zaizun bezala» (Z P, 19) ${ }^{25}$

Además de esa relación cósmica, la presencia del cuerpo de la mujer, del cuerpo sangrante, es constante a lo largo de la novela. «La centralización del cuerpo y la sangre de la mujer, su proximidad con la Naturaleza (...) escribir en tanto que flujo (de la sangre menstrual, de la leche materna, del flujo uterino), sintaxis líquida» ${ }^{26}$. «Esne epelaren usai xamurra» (ZP, 17), «Non bizi dira malkoak begietara azaltzen ez diren bitartean» (Z P, 26). «Sabeletik laister aterako zaidan odol mukitsua bezala» (Z P, 31) ${ }^{27}$. Toda esta semántica corporal nos lleva a reafirmar, parafraseando a Beatriz Ferrús y Núria Calafell $(2008)^{28}$, que esta obra está escrita desde el cuerpo y con el cuerpo. Arantxa Urretabizkaia nos muestra por primera vez en la literatura vasca una nueva representación del cuerpo de la mujer. Establece, además, un diálogo entre lo íntimo (la menstruación) y lo social (el trabajo, la política). En el encuentro de estas dos experiencias es donde se construye la identidad, la mujer como agencia. Es en esta tensión entre el cuerpo vivido (biológico) y el cuerpo social (la mirada especular) donde se subjetiviza la madre de Zergatik panpox, una madre que afronta la realidad desoladora de crear una familia monoparental a raíz del abandono, pero que, sin embargo, es consciente de que esto es lo mejor para su hijo y para ella.

Si el cuerpo femenino posee gran relevancia en el texto, asimismo adquiere una gran beligerancia el lenguaje confeccionado por la madre para el niño. A diferencia de las teorías feministas de la igualdad que desprecian este acercamiento lingüístico de la madre al niño-a, Luisa Muraro (1994) desde el feminismo de la diferencia defiende esta actitud. Muraro explica así, que las madres al hacer este uso infantil del lenguaje no se desvalorizan, sino

24. Suleiman, Susan Rubin. «Escritura y maternidad». En: DovaY, Mercedes. (ed): Maternidad y creación. Lecturas esenciales. Alba, Madrid, 2007: 151.

25. La sangre de fuego del vientre de la tierra me entra por las puntas de las raíces, como a ti te entra el sueño por las aletas de la nariz.

26. Ibíd., p. 153.

27. El olor tierno de la leche. ¿Dónde viven las lágrimas hasta que asoman a los ojos? Como el líquido viscoso que pronto saldrá de mi vientre.

28. Ver la referencia del libro de estas autoras en Referencias Bibliográficas. 
que están elaborando una estrategia para acercarse al niño-a. Esto significa para Muraro una cultura más equitativa, cercana y tolerante. «La negociación conjunta de significados, en lugar de imposición de los propios o la falta de reconocimiento de los ajenos, sería básica en una sociedad que valorase la negociación $»^{29}$.

Para concluir, debemos poner de relieve la exquisita configuración de juegos lingüísticos y literarios que brinda la madre a su hijo. «Blandiblup» ( $\mathrm{P}$, 6), «panpox, pirulo» (ZP, 17), «amatxo, muxera, muxontzi» (Z P, 22). «zu, panpox bihotzekoa, Antxon pirulero,» (ZP, 14) «ario, panpox, muxu, lehoikumea, artaburua, tira, panpox, muxu» (ZP, 18)

Esta novela, escrita en los años 70, da fiel testimonio del movimiento feminista de aquella década y su personaje protagonista es consecuencia de un dialogo con las vivencias sociales y culturales que las mujeres experimentaban en aquella época, reafirmando así la dimensión social que el narratólogo marxista Lucien Goldmann reconoce a los personajes literarios.

\subsection{Un no rotundo al Génesis, un no rotundo a la maternidad. Eta emakumeari sugeak esan zion (1999) ${ }^{30}$}

Geraldine Nichols (2003) afirma que la novela Eta emakumeari sugeak esan zion ${ }^{31}$ narra el repudio, por parte de una española de hoy, del modelo femenino dictado en el Génesis. «El título de la obra orienta su lectura, al referirse a la historia bíblica que explica por qué la mujer tiene que someterse al varón, desear al varón y parir los hijos con dolor $\aleph^{32}$. El Génesis que hace alusión al pecado original puede tener diversas lecturas, entre ellas, la más conocida hasta ahora es la que alude a Eva. Eva, al igual que Pandora es responsable de expandir el pecado, es la antónima de la Virgen María, limpia de pecado. Por lo tanto, en el desarrollo del personaje de Teresa, la protagonista, encontramos elementos explícitos que recuerdan al Génesis y obvian una intertextualidad significante de la misma.

Cristina Molina (2004) nos invita a interpretar el Génesis de una forma diferente: siendo Adán y Eva dos seres creados a semejanza de Dios, esta última en su ansia infinita de parecerse más al creador, al más grande, y ser una persona sabia como el todopoderoso, comió la manzana prohibida.

29. BengoecheA, Mercedes. Op. cit., p. 103.

30. Traducida al castellano Y la serpiente le dijo a la mujer (2000).

31. Eta emakumeari sugeak esan zion, se identificará de ahora en adelante como ES.

32. NichOls, Geraldine, Op. cit., p. 202.

Feminismo/s 18, diciembre 2011, pp. 203-223 
Pero entonces sería la mujer la fuente del conocimiento, la que ejerció la iniciativa y no el hombre. (...) Desde aquí lo femenino aparecería como sabiduría, como amor a la sabiduría, al menos como afición o pasión por el conocimiento y como poder de persuasión, todo ello impensable para una práctica de dominio patriarcal. ${ }^{33}$

Por lo tanto, el pecado de Eva no sería de desobediencia, sino de orgullo ${ }^{34}$. Partiendo de esa nueva representación, Teresa reflexiona en torno a la libertad de su cuerpo, en torno a la libertad de hacer con su vida lo que más le place y se niega rotundamente a cumplir el postulado de «parirás».

«Se dispone a leer su cuerpo de otra manera, y ve en sus síntomas la señal de que está finalizando una etapa de su vida, precisamente la pautada en el Génesis.» ${ }^{35}$ Desde el principio hasta el final del relato habla el cuerpo de Teresa del cual también podríamos afirmar que es un cuerpo adscrito a la maternidad. «Después de orinar limpiar las manos (...) Hace mucho que no manchas, ni rastro de la menstruación» $(E S, 71)^{36}$. Teresa ha sido dueña de su cuerpo y ha evitado embarazos: «Cuando aprendisteis a comprar pastillas para no quedarte embarazada» (ES, 85). La gran duda ante la maternidad: «Si por otra parte la tristeza no se cura con los hijos (si tu tristeza no se cura con la maternidad), ¿qué le pasará una madre deprimida a su hijo?» (ES, 107). Y al final, la decisión irrevocable: «Ya sabes que te está llegando la hora de tomar la última decisión (...). La de empezar a envejecer sin hijos». (ES, 162). Oñederra incorpora toda la semántica de la maternidad y del cuerpo a su discurso para, al final, decir no a la dicotomía maternidad versus cuerpo.

Sabemos que Teresa en el transcurso del relato realiza dos viajes, uno físico que inicia rumbo a Viena y otro psicológico hacia el interior. Estos viajes corporeizan mediante el uso de la segunda persona una de las experiencias más significativas de este personaje literario: la decisión de abandonar la vida laboral, familiar y por último la maternidad y decidir un futuro. Teresa lo abandona todo y emprende un viaje en solitario hacia el Mediterráneo, hacia el lugar en el que conoció el único amor de su vida, ese amor que le alertó sobre la lejanía o la imposibilidad de acercamiento entre los hombres y las mujeres. Teresa camina hacia el pasado, pero que a su vez es futuro, un futuro elegido por ella para su cuerpo cansado para la maternidad y cansado para el amor. Un futuro tranquilo sin menstruaciones, sin hijos, sin relaciones

33. Molina, Cristina. «Madre inmaculada, virgen dolorosa. Modelos e imágenes en la tradición católica». En Las mujeres y los niños primeros, Op. cit., p. 48.

34. Ibíd. p. 48.

35. NiCHOLS, Geraldine. «El procrear, pro y contra». Op. cit., p. 202.

36. Las traducciones son nuestras. 
difíciles de entender; sin embargo, será también un futuro que descansa en la muerte, en el suicidio. Rivera Garretas ${ }^{37}$ habla de la capacidad dual del cuerpo femenino, una capacidad que consiste en la creación y gestión de seres humanos y en la creación y gestión de relaciones. Teresa reniega de esta capacidad dual de su cuerpo y busca la paz, la armonía en la muerte. Pero es ella misma la que gestiona la muerte de su maternidad, de su cuerpo y la muerte de todas sus relaciones circundantes.

Teresa funciona como sujeto en el paradigma actancial. El destinador (El Génesis) invita a Teresa (sujeto) a desear la maternidad como objeto. Pero Teresa dice no y lo dice sin ayudante ni oponente porque el tema central de esta narración radica en la dificultad que entrañan las relaciones heterosexuales. Teresa reflexiona en torno a las relaciones de casada, de amante y de relaciones pasadas que se le antojan difíciles, relaciones que, en definitiva, no le satisfacen. Al analizar aspectos semánticos del personaje vemos que se autoconstruye desde sus propias experiencias. Sabemos que es un personaje literario con un alto nivel económico, con un buen trabajo y con un buen esposo, pero que nada le complace. Ante este desasosiego, el personaje inicia los dos viajes antes mencionados, pero ambos viajes comparten una característica: la soledad. El personaje de Teresa se erige por mediación de la autoconciencia

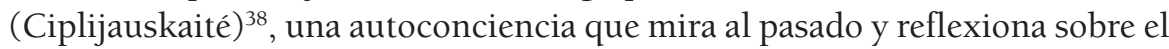
presente el cual le permite proyectar su futuro, su propia muerte.

\subsection{Sisifo maiteminez de Laura Mintegi: nuevas paternidades}

Sisifo maiteminez (2001) de Laura Mintegi y Greta (2003) de Jasone Osoro abordan como temática principal el abandono de los hijos por parte de sus madres. Beatriz Domínguez García en Hadas y brujas (1999) ha investigado las figuras de la madre ausente y la madre sustituta. En relación a la madre ausente, o la madre que abandona el hijo o la hija, afirma que es el mayor delito que puede realizar una madre porque no cumple el rol que le ha asignado la sociedad. En esta investigación hemos optado por analizar más detalladamente Sisifo maiteminez por razones obvias de espacio y porque incorpora a la narrativa vasca el contenido de las nuevas paternidades.

Biruté Ciplijauskaité (1994) calificaría esta obra escrita por Mintegi como novela psicoanalítica. La novela psicoanalítica indaga el subconsciente

37. Rivera Garretas, Milagros. El cuerpo indispensable. Significados del cuerpo. Horas y Horas, Madrid, 1996: 20.

38. Ciplijauskaité, Biruté. La novela femenina contemporánea (1970-1985). Hacia una tipología de la narración en primera persona. Anthropos, Barcelona, 1996. Ciplijauskaité trabaja este concepto a lo largo de esta obra.

Feminismo/s 18, diciembre 2011, pp. 203-223 
siguiendo un método determinado. «Lleva al paciente a evocar la infancia, intentando descubrir las causas secretas que han moldeado el estado de ánimo presente ${ }^{39}$. «Estebanek badaki hitzaren bidez kanporatzen dela inkontzientea. Subjektuaren eta hitzaren arteko harremana psikoanalisiak bakarrik jar dezakeela agerian; lengoaiak bakarrik salba dezakeela» $\left(\mathrm{SM},{ }^{40} 34\right)^{41}$. «La curación de su neurosis pasa por el afloramiento a la conciencia, es decir por la racionalización de los conflictos suprimidos en su primera infancia en la relación con su madre ${ }^{42}$.

Rosario Arias $^{43}$ señala que la personalidad femenina se define en la etapa preedípica y que se caracteriza por la relación con otros individuos, mientras que por el contrario, la masculina se define por la individualidad.

Esta teoría puede ser muy adecuada para escudriñar la personalidad de Ane, la protagonista de Sisifo maiteminez. Ane ha abandonado a sus dos hijas y a su marido y se ha ido con otro hombre. Se ha convertido en una madre ausente, y a lo largo de esta novela, Esteban, el psicoanalista, tendrá que descubrir los motivos que llevaron a Ane a estos abandonos. Suleiman ${ }^{44}$ basándose en la teoría de Nancy Chodorov, explica que las mujeres están psicológicamente preparadas para la maternidad en la medida que han heredado esa idea de la maternidad de sus madres. «Sólo un cambio radical en la crianza, compartida por padres que hagan de padres y madres por igual puede suponer un cambio importante en la psique femenina $»^{45}$. Es decir, las nuevas paternidades constituirán el fundamento de la identidad de la mujer nueva. «Ane le explica a Esteban que el embarazo y el parto no te hacen madre. Jon siendo hombre era más madre que ella» (SM, 165). Ane habla de Jon, del padre de sus hijas y da cuenta a su vez de las nuevas paternidades.

Chodorov asegura que la existencia de la maternidad se basa en el aprendizaje cognitivo de la misma. En nuestra sociedad, la madre de una niña está presente de un modo en el que el padre y otros adultos varones no lo están

39. Ibíd., p. 85.

40. Sisisfo maiteminez se identificará de ahora en adelante como SM

41. «Esteban sabe que el inconsciente se exterioriza mediante la palabra. Que sólo el psicoanálisis puede relacionar el Sujeto y la palabra, que solo el lenguaje puede salvar» ( $\mathrm{SM}, 34$, la traducción al castellano es nuestra).

42. DE LA CONCHA, Angeles. «La sombra de la madre. Un mito en la novela de las mujeres». Revista Canaria de Estudios ingleses, $\mathrm{n}^{\circ}$ 24. p.33-48, 1992: 46.

43. ARIAS, Rosario. Madres e hijas en la teoría feminista. Una perspectiva psicoanalítica. Universidad de Málaga, 2002: 44.

44. SUleiman, Susan Rubin. Op. cit., p. 128.

45. Ibíd., p. 128. 
para el niño ${ }^{46}$. Añade que la niña puede desarrollar una identificación personal con su madre porque tiene una verdadera relación con ella ${ }^{47}$.

La protagonista de la novela, Ane, habla de su madre y comenta que tuvo dos hijas a las que nunca quiso, y a pesar de que nunca las abandono físicamente, tal y como ella sí hizo, su sensación de abandono y soledad fue mayor (SM, 119). «Ama no era feliz. La ama me odiaba» (SM, 131) ${ }^{48}$. La carencia de afecto materno imprime todas sus secuelas en el carácter de la hija: ansiedad, falta de autoestima y de seguridad, pasividad, parálisis y dependencia emocional, según De la Concha ${ }^{49}$. María Angeles de la Concha en el mismo artículo recuerda lo analizado en torno a la matrofobia por Nancy Chodorov, Dorothy Dinnnerstein, Jessica Bond y Adrianne Rich y afirma que la matrofobia no es el odio a la madre sino el miedo a ser como la madre propia.

Para delimitar el significado semántico de este personaje hemos compartido las reflexiones de la feminista Milagros Rivera Garretas (2001) quien matiza que la madre personal y concreta es el problema para el feminismo porque siempre se ve como algo a mejorar.

No nos había querido lo suficiente, no había entendido nuestro anhelo de cambio social, no nos había dejado volver tarde por la noche, no había sido suficientemente libre, no había sido capaz de enseñarnos a hablar sin transmitirnos el lenguaje patriarcal... Estábamos dispuestas a honrar a un Partenón de madres simbólicas, pero la madre concreta y particular, no. ${ }^{50}$

Esto es lo que lleva a Milagros Rivera a afirmar que muchas mujeres feministas empezaron a ser madres con el objetivo de mejorar a las suyas propias y la paradoja fue que su obra éramos nosotras ${ }^{51}$.

Esta es la verdad que descubrirá Ane en el transcurrir del texto. Ane no comprende muy bien por qué ha abandonado a sus hijas y a lo largo de la narración busca la razón de ese abandono. En esa búsqueda, acompañada por su psiquiatra Esteban, descubrirá las maternidades no deseadas, obligadas y también explicitará la realidad de las nuevas paternidades, la existencia de las paternidades. Le reconocerá más autoridad maternal a su esposo Jon que a ella misma. De modo implícito, además, afirmará Ane que el ser mujer se

46. CHODOROv, Nancy. El ejercicio de la maternidad. Psicoanálisis y sociologíade la maternidad y paternidad en la crianza de los hijos. Gedisa, Barcelona, 1984: 49.

47. Ibíd, p. 260.

48. «Ama ez zen zoriontsu. Gorrotatzen ninduen» (SM, 131).

49. De la CONCHA, Ángeles. «La sombra de la madre. Un mito en la novela de las mujeres». Op. cit., p. 40.

50. RIVER GARRETAS, Milagros. Mujeres en relación. Icaria, Barcelona, 2011: 85.

51. Ibíd., p. 85.

Feminismo/s 18, diciembre 2011, pp. 203-223 
transmite de madres a hijas cognitivamente y que la relación entre padres e hijas dará lugar a una entidad de mujer diferente.

\section{Conclusiones}

Podemos afirmar como primera conclusión que de treinta novelas escritas por las escritoras vascas con personajes protagonistas femeninos en el periodo 1970-2010, veinte tratan la maternidad y hablan del cuerpo de la mujer, es decir un $66 \%$ del corpus analizado. Por lo tanto, se ratifica la teoría de la homología de Lucien Goldamnn en tanto que uno de los temas claves de pensamiento feminista se ve representado también en el ámbito literario.

El abandono aparece en muchos casos adherido a la temática de la maternidad. Vemos así madres abandonadas en un 40\% del corpus analizado y también aparece el abandono de los hijos por parte de las madres en las novelas Sisifo maiteminez y en Greta. En estos últimos casos, el abandono se convierte en el epicentro temático y todo el relato tiene como objetivo la búsqueda del motivo por el cual la madre ha optado por tomar esa decisión. Solo cuando el lector y protagonistas llegan al final del relato se descubren esos motivos, como si las madres no pudieran abandonar a sus hijos ante la mirada del interlocutor.

Es muy reveladora la actitud de Laura Mintegi en Sisifo maiteminez señalando las nuevas paternidades, retomando así la teoría de Chodorov (1984) que sostiene que la nueva mujer será fruto de las nuevas paternidades. La mujer cambiará con las nuevas relaciones entre madre e hijas y estas solo pueden transformarse con las nuevas paternidades.

Por último, a modo de conclusión general, podemos afirmar que en las últimas tres décadas el imaginario de las representaciones maternales ha ido cambiando de la misma manera que han ido transformándose las estructuras sociales que sustentan la maternidad. Un ejemplo de esta realidad sería la desaparición de la madre como transmisora de la lengua y la cultura vascas en el ámbito social y en el literario como hemos constatado en el análisis de Jostorratza eta Haria. Y obviando la afirmación del marxista George Lukács (1971) no podía ser de otra forma porque el personaje literario se construye dialécticamente con la realidad social. Concretamente, en la realidad social actual vasca, las mujeres se han escolarizado, se han incorporado al mundo laboral y se han politizado. Las leyes que defienden la igualdad, tanto las articuladas por el Gobierno español como por el Gobierno Vasco, han facilitado que la mujer vasca saliera del ámbito privado al público y se convirtiera en un agente social. Todo ello se ha producido en las últimas décadas y nuestras 
escritoras han sabido imaginarlo y recrearlo en sus producciones narrativas mediante la corporeización de los personajes protagonistas femeninos.

\section{Referencias Bibliográficas}

AGUiLAR, Pilar. «Madres de cine: entre la ausencia y la caricatura», en: De

la Concha, Angeles. y Osborne, Rraquel. (ed). Las mujeres y los niños primero. Icaria, Barcelona, 2004.

ARIAS, Rosario. Madres e hijas en la teoria feminista. Una perspectiva Psicoanálitica. Universidad de Málaga, 2002.

BAL, Mieke. Teoría de la narrativa. Cátedra, Madrid, 1985.

BARRON, Sara. «Introducción: La maternidad monoparental», en: De La

Concha, Angela.; Osborne, Raquel. (ed.): Las mujeres y los niños primero: discursos de la maternidad. Barcelona: Icaria.

BENGOECHEA, Mercedes. «Mi madre es... un hueco en el espacio: discursos poéticos y lingüísticos sobre la insignificancia materna», en Op. cit., p. 81-110.

BEAuvolr, Simone. El segundo sexo. Cátedra- Feminismos, Madrid, 2005 (1949).

BOves, Carmen. La novela. Síntesis, Madrid, 1993.

Ciplijauskaité, Biruté. La novela femenina contemporánea (1970-1985).

Hacia una tipología de la narración en primera persona. Anthropos, Barcelona, 1994.

Cixous, Hélène. La risa de la Medusa. Ensayos sobre la escritura. Anthropos, Barcelona, 2000 (1975).

ChODOROv, Nancy. El ejercicio de la maternidad. Psicoanálisis y sociología de la maternidad y paternidad en la crianza de los hijos. Barcelona, Gedisa. (1984).

DE LA CONCHA, Angeles. «La sombra de la madre. Un mito en la novela de

las mujeres». Revista Canaria de Estudios ingleses, 24. 1992, pp.33-48.

Dinnerstain, Dorothy. The Mermaid and the Minotaur. Sexual Arrengements and Human Malaise. Harper \& Roww, Nueva York, 1976.

Domínguez García, Beatriz. Hadas y brujas. La reescritura de los cuentos de hadas en escritores contemporáneos en lengua inglesa. Universidad de Huelva, 1999.

Esteban, María Luz. Antropología del cuerpo. Bellaterra, Barcelona,2004.

Ferrús, Beatriz; CAlafell, Nuria. (ed.). Escribir con el cuerpo. Editorial UOC. SL, Barcelona, 2008.

FIRESTONE, Sulamith. La dialéctica del sexo: en defensa de la revolución feminista. Kairós, Barcelona, 1976.

Goldmann, Lucien. Para una sociología de la novela. Ciencia Nueva, Madrid, 1967 (1964).

Greimas, Algirdas Julius. La semiótica del texto, ejercicios prácticos. Paidós, Madrid, 1983. 
IMAZ, Elixabete. Mujeres gestantes, madres en gestación. Representaciones, modelos y experiencia en el tránsito a la maternidad de las mujeres vascas contemporáneas. UPV, Bilbo, 2007.

IRIGARAY, Luce. Speculum espéculo de la otra mujer, Saltés, Barcelona, 1978 (1974). KogAN, Liuba. «Jóvenes y viejos: ¿el cuerpo como locus de identidad?». Revista Latinoamericana de Estudios sobre Cuerpos, emociones y Sociedad. 5. Argentina, 2011. pp.15-24.

KortaZAR, Jon. Euskal literatura XX. Mendean. Prames. Las Tres Sorores, Zaragoza, 2003.

LASARTE, Gema. Pertsonaia protagonista femeninoen ezaugarriak eta bilakaera euskal narratiba garaikidean. UPV/EHU, Bilbo, 2011.

LUCKÁCS, George. Teoría de la novela. Edhasa, Barcelona, 1971 (1920).

LLONA, Miren. «Patriotic Mothers of Basque Nationalism: Women's Action during the Spanish Second Republic in the Basque Country», en Esteban, Mari Luz y Amurrio Milagros (ed.): Feminist Challenges in the Social Sciences Gender Studies in the Basque Country Reno, Center of Basque Studies, University of Nevada, 2010.

MitChell, Julia. Woman's Estate. Harmondswort, Penguin, 1971.

Muraro, Luisa. El orden simbólico de la madre. Horas y Horas, Madrid, 1994.

NicHOLS, Geraldine. «El procrear, pro y contra», en: REDONDO Alicia, (coor): Mujeres novelistas. Narcea, Madrid, 2003.

OlAZIREGI, María José. Euskal eleberriaren historia: Labayru Ikastegia Amorebieta Etxanoko Udala, 2002.

RicH, Adrianne. Nacemos de mujer. La maternidad como experiencia e institución. Cátedra-Feminismos, Madrid, 1996.

Rimon-Kenan, S. Narrative Fiction; Contemporany Poetics. Methuen, Londres, 1983.

Rivera Garretas, Milagros. El cuerpo indispensable. Significados del cuerpo. Horas y Horas, Madrid,1996.

River GARretas, Milagros. Mujeres en relación. Icaria, Basrcelona, 2001.

RIVERA GARRETAS Milagros. La diferencia sexual en la historia. PUV, Valencia, 2005. RUDDICK, Sara. «Maternal Thinking», en A. Trebilcot (ed): Mothering Essays in Feminist Theory, Totowa/New Jaersey, Rowman \& Allanheld Publishers, 1984.

SAU, Victoria. Ser mujer: el fin de una mujer tradicional. Icaria, Barcelona, 1993.

SHIVA, Vandana. Abrazar la vida. Mujer, ecología y desarrollo. Horas y horas, Madrid, 1995.

Suleiman, Susan Rubin. «Escritura y maternidad», en: Dovay, M. (ed): Maternidad y creación. Lecturas esenciales. Alba, Madrid, 2007.

VEGA, María José. Imperios de papel. Introducción a la crítica postnacional. Crítica, Barcelona, 2003. 


\section{Bibliografía corpus}

ARRIETA, Jolanda. 1998. Jostorratza eta haría. Kutxa Fundazioa

BORDA, Itxaro. 1995. Bizi nizano munduan. Zarautz: Susa.

ETXEBERRIA, Aitziber. 2003. Tango urdina. Donostia: Erein

- 2007. 31 baioneta. Donostia: Erein.

GONZÁlEZ, Sonia. 2003. Ugerra eta Kedarra. Lizarra:Txalaparta.

JAIO, Karmele. 2006. Amaren eskuak. Donostia: Elkar.

- 2009. Musika airean. Donostia: Elkar.

JimEnEZ, Irati. 2009. Nora ez dakizun hori. Donostia: Elkar.

MARTIN SAMPEDRO, Eukene. 1985. Lau sasoitako zipriztinak. Zarautz: Susa.

MinTEGI, Laura. 1986. Bai baina ez. Zarauz: Susa.

- 1994. Nerea eta biok. Lizarra: Txalaparta.

- 2001. Sisifo maiteminez. Lizarra: Txalaparta.

OñederA, Lourdes.1999. Eta emakumeari sugeak esan zion. Donostia: Erein.

Osoro, Jasone. 2003. Greta. Donostia: Elkar.

- 2009. Bi marra arrosa. Donostia: Elkar.

UrretabiZaKaiA, Dorleta.2006. Jaione. Donostia: Kutxa.

Urretabizkaia, Arantxa. 1979. Zergatik Panpox. Donostia: Hordago.

- 1998. Koaderno Gorria. Donostia: Erein.

- 2010. Hiru Mariak. Donostia: Erein. 